\title{
Incidence of Virulent Factors in Staphylococci Isolated from Clinical and Foods Specimens in Egypt
}

Fifi M. Reda ${ }^{\#}$, Rashad M. Kebeish, Azza A. Abou Zeid and Marwa N. Elsharawy Botany and Microbiology Department, Faculty of Science, Zagazig University, Zagazig, Egypt.

\begin{abstract}
NE HUNDRED Gram positive staphylococci isolates were isolated from 80 clinical specimens and 20 food samples using Baird Parker and mannitol salt agar media. Sixty isolates out of $80(75 \%)$ isolated from clinical specimens were found to be coagulase positive staphylococci while the other 20 isolates $(25 \%)$ were proved to be coagulase negative staphylococci. Meanwhile, all staphylococci isolated from food samples (20 isolates) were found to be coagulase negative isolates. The antibiotic susceptibility profile of all isolated staphylococci against 11 antibiotics indicated that 8 isolates were found to be resistant to more than 4 antibiotics which means that they are multi-drug resistant (MDR). Following the key of Bergey's Manual of Determinative Bacteriology, the 2 coagulase positive clinical isolates (41 and 66) were preliminary identified as $S$. aureus and the other 6 coagulase negative staphylococci isolates were found to be related to different species of Staphylococcus genus. Using specific designed primers, some toxin target genes namely: entA, ent $C$, entDl and $h l g$ were screened in the 8 selected MDR isolates. The isolates encoded 7 and 11, preliminary identified as $S$. saprophyticus 7 and S. xylosus 11, showed obvious significant amplicons of toxins genes entA, entDl and $h l g$ while the clinical isolates 41 and 66 which were preliminary identified as $S$. aureus, possessed entA and $h l g$ genes only. Identification of coagulase negative S. xylosus 11 containing more than 3 toxin genes was confirmed by amplification of 16S rRNA gene which showed $99 \%$ similarity with $S$. xylosus strain. This sequence was deposited in Genbank under accession number MH118574.
\end{abstract}

Keywords: Genus Staphylococcus, Virulence factors, Pathogenicity, Multidrug resistance (MDR), Enterotoxins genes.

\section{Introduction}

Coagulase-negative staphylococci (CNS) are the most frequent constituent of the normal flora of components of various parts of the skin and of the respiratory and gastrointestinal system mucosa of human; they may also appear in animals and foods tuff (Longauerova, 2006 and Becker et al., 2014). These organisms are common contaminants in clinical specimens as well as increasingly recognized as agents of clinically significant infection, including bacteremia and endocarditis (Chu et al., 2008).

Staphylococcus enterotoxins are relatively resistant to heat and to the proteolytic enzymes trypsin, pepsin and renin, which enables their passage through the gastrointestinal tract without losing activity (Huy, 1994). At least thirty four different extracellular proteins are produced by pathogenic Staphylococcus strains, and several of them already play a definite role in the pathogenesis of recognized staphylococcal diseases (Lisa, 2004 and Vianello, 2006).

Virulence and pathogenicity had been commonly related to coagulase positive $S$. aureus species as common clinical and foodborne pathogens. Enterotoxins are mainly produced by coagulase positive staphylococci (Le Loir et al., 2003 and Chiang et al., 2008). Meanwhile, some coagulase-negative staphylococci (CNS) are reported to be involved in a variety of human and animal infections (Kloos \& Bannerman, 1995). CNS can contaminate foods because humans are common carriers of these microorganisms and some may be related to specific human infections (Bergdoll, 1995).

Some $S$. aureus strains and coagulase-negative staphylococci secreted staphylococcal virulence factors as staphylococcal enterotoxins (SEs) and toxic shock syndrome toxin 1 (TSST-1) (Novick et al., 2001 and Cunha \& Calsolari, 2008). Klotz et

\#Corresponding author email: afmo67@yahoo.com Tel: +20-1010092088

DOI: $10.21608 /$ ejbo.2018.1844.1130

C2018 National Information and Documentation Center (NIDOC) 
al. (2003) detected S. aureus enterotoxins A, B, C1, and D genes which encoding as SEA (entA), SEB $(e n t B)$, SEE (entE) and SED (entD) by using realtime fluorescence PCR assay. Also, Staphylococci produces five different membrane damaging toxins, four hemolysins (alpha-, beta-, gamma- and deltahemolysin) and leukocidin (Koneman, 1997). The alpha-hemolysin encodes hla is dermonecrotic and neurotoxic and can be lethal in a variety of animal systems contributing role in formation of abscesses (Gray \& Kehoe, 1984). Gamma-hemolysin toxins are characterized by two non-associated secreted proteins, referred to as $\mathrm{S}$ and $\mathrm{F}$ components. The gamma toxin locus expresses two class $\mathrm{S}$ components ( $\mathrm{HlgA}$ and $\mathrm{HlgC}$ ) and one class $\mathrm{F}$ component (HlgB) (Supersac et al., 1998).

The recognition of CNS as etiological agents may be due to the valorization of this group of organisms as opportunistic pathogens and to the increasing use of invasive procedures such as intravascular catheters and to prosthetic interference (da Cunha et al., 2006). Evidence indicates that pathogenicity might be related to the production of an extracellular polysaccharide, known as slime that permits these microorganisms to adhere to smooth plastic surfaces, colonizing catheters, prosthetic heart valves, pacemakers, and joint prostheses (Vogel et al., 2000). According to Koneman et al. (1997), CNS produce other virulence factors, such as hemolysins, lipases, proteases, and toxins.

Recent reports of the involvement of some coagulase negative staphylococci in a variety of human and animal infections have raised interest (Gillespie et al., 2009 and Becker et al., 2014). ElJakee et al. (2013) reported that CNS have emerged to be pathogens causing intramammary infections in Egyptian dairy herds. The current study was conducted to investigate the incidence of coagulase negative and positive staphylococci isolated from clinical and food samples and study their virulence and antibiotic susceptibility profile.

\section{Materials and Methods}

\section{Samples collection}

This study was conducted on eighty clinical specimens of pus, sputum and urine collected from eighty patients admitted to Zagazig University Hospital, Zagazig, Egypt in the period from January to March, 2014. Also, the study was conducted on twenty isolates from different sources of food (meat and meat products; milk and milk products) which collected from Sharkia Markets in same the period. The specimens were collected and transported according to Murray et al. (2007).

\section{Isolation, purification and identification of bacterial isolates}

Swabs of clinical specimens were directly streaked on agar surface of specific media plates, meanwhile $10 \mathrm{~g}$ of food samples were homogenized and suspended in $90 \mathrm{ml}$ sterile peptone water and incubated at $37^{\circ} \mathrm{C}$ for $3 \mathrm{~h}$. Further on, loopful inocula of prepared food samples were streaked on surface of agar specific media; Baird Parker agar (BairdParker et al., 1969) and Mannitol salt agar (Merlino et al., 1996). Plates were incubated at $37^{\circ} \mathrm{C}$ for $24 \mathrm{~h}$.

Morphological and physiological characteristics of the selected isolates were studied. Media and reagent were prepared according to standard procedures as described by Lennette et al. (1979). The selected bacterial isolates were preliminary identified according to Holt et al. (1994).

Identification of selected isolate was confirmed by sequencing of partially amplified $16 \mathrm{~S}$ rRNAgene. The DNA was extracted from bacteria following the protocol recommended by Sambrook \& Russell (2001). 16S rRNA gene was sequenced using 5'-AGAGTTTGATCC TGGCTCAG-3' as forward primer and 5'-GGTTACCTTGTTACGACTT-3' as reverse primer. NCBI BLAST program (www.ncbi. nlm.gov/blast) and ClastalW2 program (https:// www.ebi.ac.uk/Tools/msa/clustalw2/) for sequence similarity and phylogenetic analyses was used to assess the similarities of the obtained 16S rRNA gene sequence in Genbank database.

\section{Antibiotic susceptibility test}

Susceptibility of the tested bacterial isolates to eleven antibiotics (vancomycin, amikacin, mipenem, ampicillin, cefotaxime, norfloxacin, ciprofloxacin, ofloxacin, gentamicin, tetracycline and ampicillin/sulbactam (unasyn) was determined using disk diffusion technique according to NCCLS (1999). These antibiotics were selected depending on their different groups and their action in Gram positive bacteria.

Determination of virulence factors produced by selected isolates

The selected MDR isolates resistant to more than 4 antibiotics were screened for their capability to produce specific virulence factors, namely, hemolysin, protease and lecithinase enzymes on 
blood agar, casein agar and egg yolk agar media, respectively, at $35^{\circ} \mathrm{C}$ for $24 \mathrm{~h}$ using agar well diffusion assay according to Klaenhammer (1988). Also, coagulase (Chessbrough 2000); gelatinase (Collee \& Marr, 1996), fibrinolytic activities (Christie \& Wilson, 1941) and biofilm formation (Mathur et al., 2006) by selected isolates were tested.

Screening of the selected strains for target toxin genes using conventional polymerase chain reaction $(P C R)$ technique

DNA templates of the tested bacterial cultures were prepared according to the method described by Osek (2000). Four pairs of primers specific for genes; ent $\mathrm{A}$, ent $\mathrm{D} 1, h l g$ and ent $\mathrm{C} 1$ were designed as shown in Table 1 and described previously by Ye et al. (2012).

All the reactions for PCR analyses were carried out using $0.25 \mu \mathrm{l}(1.25 \mathrm{U})$ Taq DNA polymerase (Thermoscientific, USA). A total reaction volume of $25 \mu \mathrm{l}$ was used, including $2.5 \mu \mathrm{l}$ of $10 \mathrm{x}$ PCR reaction buffer, $0.5 \mu \mathrm{l}$ dNTPs mixture $(100 \mu \mathrm{M})$, $0.5 \mu \mathrm{l}$ of each primer $(10 \mathrm{pmol})$, and $2 \mu 1$ template DNA were added. PCR amplification was carried out using a Master Cycler Gradient PCR. In all cases, The PCR program was $2 \mathrm{~min}$ at $95^{\circ} \mathrm{C}$ initial denaturation step followed by 35 cycles $(30 \mathrm{sec}$ at $95^{\circ} \mathrm{C}$ denaturation, 30sec primer annealing step at $56^{\circ} \mathrm{C}$ and $1 \mathrm{~min}$ extension period at $72^{\circ} \mathrm{C}$ ). PCR products were visualized on a $1 \%(\mathrm{w} / \mathrm{v})$ agarose gel containing $(2 \mu \mathrm{l})$ ethidium bromide as described by Sambrook et al. (1989). 1x Tris-acetate-EDTA (TAE) buffer was used for gel preparation and as running buffer. The expected amplicons was visualized using UV- transilluminator and Gel doc 100 systems (Biorad, Germany). 1Kbp DNA plus ladder was used to determine the molecular size of the resulted amplicons.

\section{Sequencing of amplified genes}

Sequencing of PCR products was performed for all amplified genes at GATC Company using ABI3730xl DNA sequencer system. All PCR products were firstly column purified using PCR product purification kit (Qiagen, Germany). Toxins genes (ent $\mathrm{A}$, ent $\mathrm{C} 1$, ent $\mathrm{D} 1$ and $h l g$ ) were sequenced using the designed forward primers listed in Table 1.

\section{$\underline{\text { Results and Discussion }}$}

Members of the Staphylococcus genus, especially Staphylococcus aureus, are the most common pathogens found in hospitals and in community-acquired infections (Vaidieki et al., 2007). Some of their pathogenicity is associated with enzyme and toxin production (Casadevall \& Pirofski, 2009). S. aureus was the most studied species in the genus. During the last decade, increased infections caused by coagulase-negative staphylococci (CNS) have been reported (Gillespie et al., 2009). Therefore, further studies on virulence factors that have not yet been completely elucidated in order to characterize the pathogenic potential of this group of bacteria. Several staphylococcal species produce enterotoxins; a family of related proteins responsible for many diseases, such as the toxic-shock syndrome, septicemia and food poisoning. To date, 23 different enterotoxin types have been identified besides to TSST-1, and they can be divided into five phylogenetic groups (Vasconcelos \& da Cunha, 2010). The mechanism of action of these toxins includes super antigen activity and emetic properties, which can lead to biological effects of infection (Vasconcelos \& da Cunha, 2010). Various reports have described the isolation of CNS and the association of these bacteria with clinically significant diseases (Azih \& Enabulele, 2013).

TABLE 1. Primer sequences and molecular sizes of the expected amplicons of target the six tested enterotoxin genes.

\begin{tabular}{lccc}
\hline Target gene (s) & Primer name & Primer sequence & $\begin{array}{c}\text { Product size } \\
\text { (bps) }\end{array}$ \\
\hline \multirow{2}{*}{ Enterotoxin A (entA) } & entA-FW & 5'-TCA TTG CCC TAA CGT TGA CAA-3' & 774 \\
& entA-Rev & 5'-CCT CTG AAC CTT CCC ATC AA-3' & \\
Enterotoxin D1 (entDl) & entD1-FW & 5'-CCG CGC TAA ATA ATA TGA AAC A-3' & 777 \\
& entD1-Rev & 5'-AAA TAG CGC CTT GCT TGT G-3' & \\
Gamma hemolysin $(h l g)$ & hlg-Fw & 5'-AGA AGA TAT CGG CCA AGG TG-3' & 1200 \\
& hlg-Rev & 5'-TCA ACG GCT AAA CGA TGT CT-3' & \\
Enterotoxin C1 (entCl) & entC1-FW & 5'-AGA GAG CCA ACC AGA CCC TA-3' & 801 \\
& entC1-Rev & 5'-CCA TTC TTT GTT GTA AGG TGG A-3' & \multirow{2}{*}{} \\
\hline
\end{tabular}


In the current study one hundred Gram positive staphylococci isolates were isolated from 80 clinical specimens (pus, sputum and urine) and 20 food samples (raw meat, raw poultry meat, raw milk, beef and cheese) using Baird Parker and mannitol salt agar media. Sixty isolates out of eighty $(75 \%)$ were isolated from clinical specimens and were found to be coagulase positive staphylococci while the other 20 isolates $(25 \%)$ were proved to be coagulase negative staphylococci. Meanwhile, all staphylococci isolated from food samples (20 isolates) were found to be coagulase negative isolates. All isolates were Gram-positive cocci in cluster arrangement, non-motile, nonsporulated and catalase positive (Data not shown). S. aureus is an extraordinary versatile pathogen, and it can cause a large spectrum of infections, from mild to severe and fatal (Lowy, 1998). S. aureus is known as one of the most frequent pathogens in both community and nosocomial infections, and it can cause septicemia, endocarditis, osteomyelitis, abscesses, pneumonia, wound infections, impetigo, cutaneous rash, in addition to various toxin mediated diseases (Foster, 2004 and 2005). The variety of such spectrum of clinical manifestations is mostly dependent on the numerous virulence factors produced by each strain (Le Loir et al., 2003). S. aureus is one of the most common clinical and food borne pathogens. The infections of $S$. aureus can be acquired through both hospital and community settings including food poisoning (Kadariya et al., 2014). El-Jakee et al. (2013) studied the prevalence and isolation of CNS from the examined subclinical mastitic cattle, buffaloes, sheep and goats with percentages of $16.6 \%, 59.4 \%, 50 \%$ and $55.6 \%$, respectively.

Coagulase-negative staphylococci (CNS) are a diverse group of commensals inhabiting the skin and mucous membranes of humans and animals. However some species of CNS are known as important opportunistic human pathogens. The role of CNS as animal and human pathogens is less understood. Recently, interest in (CNS), had increased due to their increasing importance in hospital infection, particularly in nosocomial bacteremia (Campoccia et al., 2006) and food poisoning outbreaks (Guimaråes et al., 2013 and Tarekgne et al., 2015).

The potential threat of antibiotic resistance in food and healthcare associated bacteria is a concern for public health. The antibiotic susceptibility profile of all isolated staphylococci (100 isolates) against 11 antibiotics, indicated that 8 isolates ( 2 coagulase and 6 non coagulase staphylococci) were multi-drug resistant (MDR) to more than 4 antibiotics. The clinical isolates showed high vancomycin susceptibility $(98.75 \%)$ followed by amikacin, and imipenem with $92.5 \%$, and $86.25 \%$ susceptibility, respectively (Table 2 ). On the other hand, $73.75 \%$ of total tested bacterial isolates were resistant to ampicillin while $23.75 \%, 22.5 \%$ and $21.25 \%$ were resistant to cefotaxime, norfloxacin and ciprofloxacin, respectively. Regarding food isolates, vancomycin, imipenem, norfloxacin, ofloxacin, amikacin, gentamicin, and ciprofloacin were highly effective with susceptibility percentage $(100 \%)$ followed by tetracycline with $80 \%$, meanwhile, $70 \%$ of tested bacteria were resistant to ampicillin. Similarly, Gundogan \& Ataol (2013) studied the antimicrobial susceptibility profiles of 209 saphylococci and their results revealed high percentage of resistance for ampicillin (33.8\%), tetracycline $(26.3 \%)$, erythromycin $(20.6 \%)$, methicillin $(17.2 \%)$ and gentamicin (12.4\%). Meanwhile, susceptibility to vancomycin, chloramphenicol, amikacin and clindamycin were $100 \%$ for all isolates. Also, El-Zawahry et al. (2013) reported that the most effective antibiotic for clinical bacterial isolates was amikacin (80\%) followed by nitrofurantoin and norfloxacin with susceptibility percentage, $76.25 \%$ and $71.25 \%$, respectively. Reda et al. (2017) reported that gentamycin $(76 \%)$ was the most effective antibiotic against clinical bacterial isolates followed by amikacin and nitrofurantoin. Nunes et al. (2015) reported that the CNS strains isolated from commercial and artisanal salami showed multi-resistance to several antimicrobials of therapeutic importance in both human and veterinarian medicine, such as $\beta$-lactams, vancomycin, and linezolid. Some species of coagulase negative staphylococci can present health risks, since they have shown resistance to antibiotics of therapeutic importance, such as beta lactams. Due to the intensive and indiscriminate use of antibiotics for human and veterinarian therapeutic purposes, multi-resistant staphylococci strains might be selected when introduced in food matrices acting as reservoir of multi-resistant microorganisms that can spread by the consumption of an apparently safe food. This opinion has been emphasized by several authors (Babic et al., 2011 and Nunes et al., 2015). 
TABLE 2. Comparative susceptibility of all bacterial isolates from clinical and food sources against different antibiotics.

\begin{tabular}{|c|c|c|c|c|c|c|c|c|c|}
\hline \multirow{2}{*}{$\begin{array}{l}\text { Isolate } \\
\text { source }\end{array}$} & \multirow{2}{*}{ Antibiotic } & \multirow{2}{*}{ Symbol } & \multirow{2}{*}{$\begin{array}{l}\text { Conc. } \mu g / \\
\text { disc }\end{array}$} & \multicolumn{2}{|c|}{ Resistant (R) } & \multicolumn{2}{|c|}{$\begin{array}{c}\text { Intermediate } \\
\text { (I) }\end{array}$} & \multicolumn{2}{|c|}{ Susceptible (S) } \\
\hline & & & & No. & $\%$ & No. & $\%$ & No. & $\%$ \\
\hline \multirow{7}{*}{ 胥 } & Imipenem & IMP & 10 & 7 & 8.75 & 4 & 5.00 & 69 & 86.25 \\
\hline & Norfloxacin & NOR & 10 & 18 & 22.50 & 4 & 5.00 & 58 & 72.50 \\
\hline & Ofloxacin & OFX & 5 & 13 & 16.25 & 2 & 2.50 & 65 & 81.25 \\
\hline & Amikacin & $\mathrm{AK}$ & 30 & 1 & 1.25 & 5 & 6.25 & 74 & 92.5 \\
\hline & Ampicillin & AM & 10 & 59 & 73.75 & 0 & 0 & 21 & 26.25 \\
\hline & Tetracyclin & $\mathrm{TE}$ & 30 & 16 & 20.00 & 1 & 1.25 & 63 & 78.75 \\
\hline & Gentamicin & $\mathrm{CN}$ & 10 & 12 & 15.00 & 3 & 3.75 & 65 & 81.25 \\
\hline \multirow{9}{*}{$\begin{array}{l}\text { D̊ } \\
8 \\
\text { I. }\end{array}$} & Vancomycin & VA & 30 & 0 & 0 & 0 & 0 & 20 & 100 \\
\hline & Imipenem & IMP & 10 & 0 & 0 & 0 & 0 & 20 & 100 \\
\hline & Norfloxacin & NOR & 10 & 0 & 0 & 0 & 0 & 20 & 100 \\
\hline & Cefotaxime & CTX & 30 & 8 & 40 & 0 & 0 & 12 & 60 \\
\hline & Ofloxacin & OFX & 5 & 0 & 0 & 0 & 0 & 20 & 100 \\
\hline & Amikacin & $\mathrm{AK}$ & 30 & 0 & 0 & 0 & 0 & 20 & 100 \\
\hline & Ampicillin & AM & 10 & 14 & 70 & 0 & 0 & 6 & 30 \\
\hline & Tetracyclin & $\mathrm{TE}$ & 30 & 4 & 20 & 0 & 0 & 16 & 80 \\
\hline & Gentamicin & $\mathrm{CN}$ & 10 & 0 & 0 & 0 & 0 & 20 & 100 \\
\hline
\end{tabular}

The virulence factors of microorganisms in the Staphylococcus genus include surface components, such as the capsule, peptidoglycans, teichoic acid, protein A, collagen cell attachment protein, enzymes such as lipases, esterases, fatty-acid modifying enzymes, various proteases, hyaluronidase, hydrolytic enzymes, desoxirribonucleases, coagulase, catalase, betalactamase, staphylokinase, and various toxins, such as exfoliative toxin $\mathrm{A}$ and B, leukocidins, enterotoxins, TSST-1 and alpha, beta, gamma and delta hemolysins (Cunha et al., 2006). Staphylococcal toxins can be divided into two groups according to their capacity for lysing cells: Hemolysins or cytotoxins, which are capable of producing lesion directly to the outer membrane of target cells (Freer \& Arbuthnott, 1982), and the so-called superantigen toxins, which do not present direct lytic action, but can produce lesions through the overproduction of cytotoxins from activated T-cells and from monocytes/macrophages (Herman, 1991).

In the present study, eight isolates encoded $41,60,61,66,67,69,7$ and 11 were selected as multi-drug resistant (resistant to 4 or more antibiotics) and examined for virulence factors and the presence of target enterotoxins genes (ent $\mathrm{A}$, ent $\mathrm{D}_{1}, h l g$, ent $\left.\mathrm{C}_{1}\right)$. Results in Table 3 revealed apparent lecithinase activity in 7 isolates out of 8 (87.5\%), hemolytic activity and biofilm formation in 5 isolates $(62.5 \%)$. Meanwhile, amylase and fibrinolytic activities were detected in 2 isolates only $(25 \%)$ and gelatinase activity was completely absent in all selected MDR isolates. According to Holt et al. (1994), the 2 coagulase positive clinical isolates (encoded as $41 \&$ 66) were preliminary identified as $S$. aureus and the other 6 non coagulase staphylococci were found to be related to different species of Staphylococcus genus; S. saprophyticus 7, S. xylosus 11, S. epidermidis 60 and Staphylococcus sp. 67 and 69. In this connection, Gundogan \& Ataol (2013) reported that 175 out of 209 total Staphylococci $(83.7 \%)$ isolated from raw calf meat (minced), chicken drumsticks, raw milk, ice cream and white cheese samples were coagulase negative staphylococci and $34(16.3 \%)$ were coagulase-positive staphylococci. The majority of Staphylococcus isolates showed 
biofilm formation (75.1\%) and slime formation (68.4\%). The frequency of positive protease and lipase production for $S$. aureus isolates were 23.5 and $11.8 \%$, respectively. Meanwhile, proteolytic and lipolytic activitiy were not found in the other Staphylococcus species. Fowoyo \& Ogunbanwo (2016) investigated 225 CNS isolates for virulence traits and the standard and genotypic analysis revealed the production of biofilm in 200 isolates (78.4\%), $\alpha$-haemolysin in $136(53.3 \%)$, $\beta$-haemolysin in $43(16.9 \%)$, DNase in 199 $(78.0 \%)$, TNase in $29(11.4 \%)$, hyaluronidase in $125(49.0 \%)$.

With the development of molecular biology, some techniques have been proposed for the detection of the genes responsible for toxins production. At present, Polymerase chain reaction (PCR) is one of the most frequently used methods as it enables the identification of the genes responsible for enterotoxin production with high sensitivity and specificity. Protocols for gene detection have been developed by using the sequence of oligonucleotides obtained by the computerized analysis of gene sequences (Jarraud, 1999). When investigating samples of CNS and S. aureus isolated from different foods in French restaurants, Rosec \& Gigaud (2002) observed that none of the 74 isolated CNS samples contained toxigenic genes whereas, of the $258 \mathrm{~S}$. aureus samples tested, 76 showed toxin genes. In Brazil, when investigating the presence of toxigenic genes in CNS samples isolated from food by the PCR technique, Cunha et al. (2006) found $10 \%$ of samples positive, of which $25 \%$ were positive for sec-1 gene and $75 \%$ for sea gene.
In the present study, the eight selected MDR strains were examined for presence of target enterotoxin genes namely; ent $\mathrm{A}$, ent $\mathrm{D}_{1}, h l g$ and ent $\mathrm{C}_{1}$ using the total bacterial DNA isolated from the eight MDR strains as a PCR template. The resulting amplicons of PCR using designed specific primers, previously mentioned in materials and methods, are marked with arrows in Fig. 1 and 2. Incidence of target genes in tested strains was strain dependent and both S. saprophyticus 7 and S. xylosus 11 strains showed obvious significant amplicons of toxins genes ent $\mathrm{A}$, ent $\mathrm{D} 1$ and $h l g$ in addition to presence of entCl in S. xylosus 11 strain only. On the other hand, the clinical strains $S$. aureus 41, S. epidermidis 60 and $S$. aureus 66 possessed entA and $h l g$ genes only. Further amplification of toxins genes (entA, ent $\mathrm{C} 1$, ent $\mathrm{D} 1$ and $h l g$ ) in $S$. xylosus 11 and $S$. aureus 41 strains was performed (Fig. 3 and 4). Isolation and sequencing of amplified genes and their alignment with database in Genbank confirmed similarity of ent A gene in both isolates S. xylosus 11 and S. aureus 41 to that of $S$. aureus strain ROF2 with accession JN687471.1 and AY827552.1, respectively. Meanwhile, entD1 gene in $S$. xylosus 11 was similar to that of $S$. xylosus strain S170 with accession CP013922.1. hlg gene amplified from S. xylosus 11 was similar to that of S. xylosus strain S170 with accession CP013922.1. Moreover, Genbank alignment of amplified gene of ent $\mathrm{C}_{1}$ in $S$. xylosus 11 showed similarity to $S$. aureus strain HUV05-03 with accession CP007679.1. All the alignment and similarities of the desired genes with Genbank sequences are shown in Table 4.

TABLE 3. Screening of the selected MDR isolates for production of certain virulence factors.

\begin{tabular}{|c|c|c|c|c|c|c|c|c|}
\hline \multirow[b]{2}{*}{ Test } & \multicolumn{6}{|c|}{ Clinical specimens } & \multicolumn{2}{|c|}{ Food sources } \\
\hline & SA41 & SA66 & SE60 & SS61 & Ssp.67 & Ssp.69 & SS7 & SX11 \\
\hline Lecithinase & + & + & + & + & + & + & + & - \\
\hline Coagulase & + & + & - & - & - & - & - & - \\
\hline Gelatinase & - & - & - & - & - & - & - & - \\
\hline Hemolysis & + & + & + & + & - & + & - & - \\
\hline Protease & + & + & + & - & - & - & - & - \\
\hline Amylase & + & + & - & - & - & - & - & - \\
\hline Biofilm formation & + & + & - & + & - & - & + & + \\
\hline $\begin{array}{l}\text { Fibrinolytic } \\
\text { activities }\end{array}$ & + & + & - & - & - & - & - & - \\
\hline
\end{tabular}

S. aureus $41=\mathrm{SA} 41$, S. aureus $=\mathrm{SA} 66$, S. epidermidis $60=\mathrm{SE} 60$, S. saprophyticus $61=\mathrm{SS61}$, Staphylococcus $\mathrm{sp} .67=\mathrm{Ssp} .67$, Staphylococcus sp.69=Ssp.69, S. saprophyticus 7=SS7, S. xylosus 11=SX11 


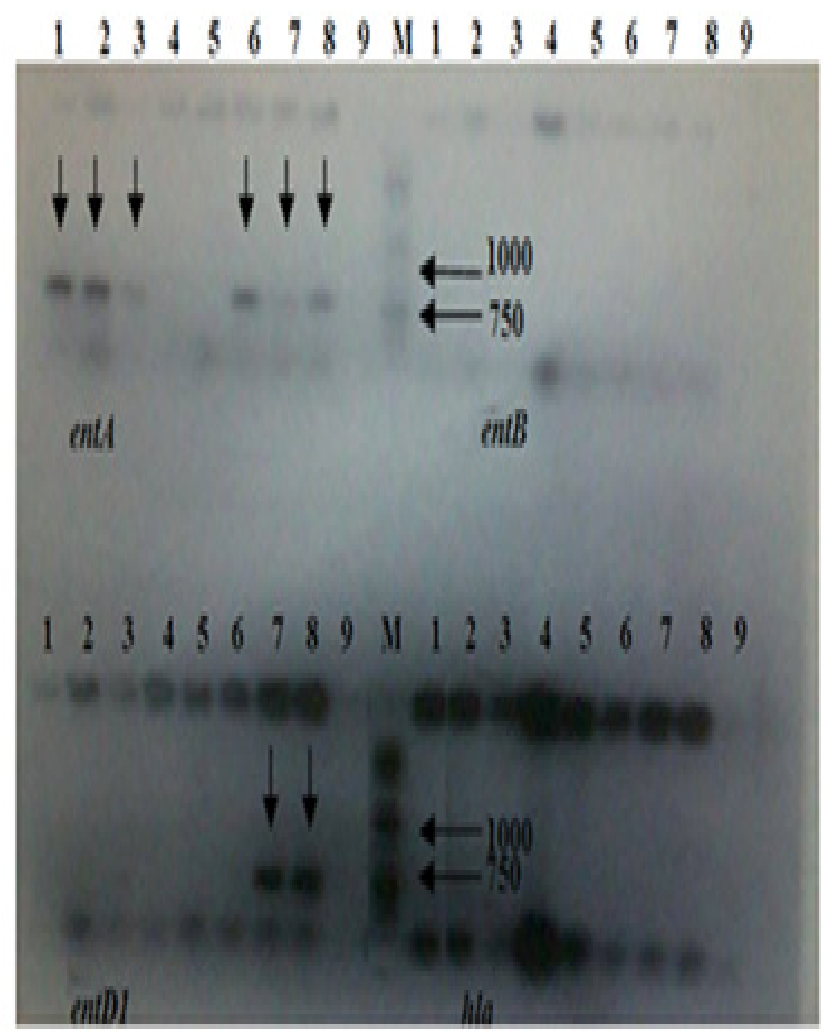

Fig. 1. Photo of agarose gel showing PCR products using specific primers for toxin target genes: entA and entD1 in the eight tested bacterial strains.

Lane M: $1 \mathrm{k}$ bp DNA marker. Lanes 1, 2, 3, 4, 5, 6, 7 and 8 are loaded with products of bacterial strains; $S$. aureus $41, S$. aureus 66, S.epidermidis 60, S. saprophyticus 61, Staphylococcus sp. 67 and Staphylococcus sp. 69, S. saprophyticus 7 and S. xylosus 11, respectively and lane 9 is negative control. The resulting amplicons having molecular size 774 bp show presence of gene entA in strains $S$. aureus 41 , S. aureus 66, S. epidermidis 60, Staphylococcus sp. 69, S. saprophyticus 7 and $S$. xylosus 11, gene entD1 with molecular size 777bp present in S. saprophyticus 7 and S. xylosus 11 strains.

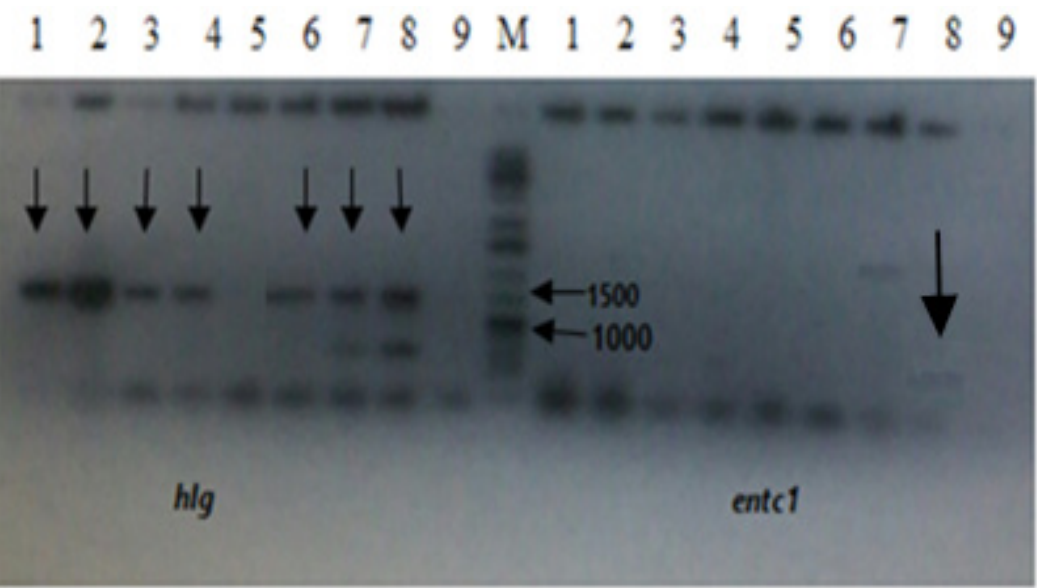

Fig. 2. Photo of agarose gel showing PCR products using specific primers for toxins target genes: hlg and entC1 in the eight tested bacterial strains.

Lane M: $1 \mathrm{k}$ bp plus DNA ladder. Lanes 1, 2, 3, 4, 5, 6, 7 and 8 are loaded with products of bacterial strains; $S$. aureus $41, S$. aureus 66, S. epidermidis 60, S. saprophyticus 61, Staphylococcus sp. 67 and Staphylococcus sp. 69, S. saprophyticus 7 and S. xylosus 11, respectively and lane 9 is negative control. The resulting amplicons show presence of gene $h l g$ with molecular size $1200 \mathrm{bp}$, in strains S. aureus 41, S. aureus 66, S. epidermidis 60, Staphylococcus sp. 69, S. saprophyticus 7 and S. xylosus 11. Gene entC1 (801 bp) was detected only in $S$. xylosus 11 strain. 


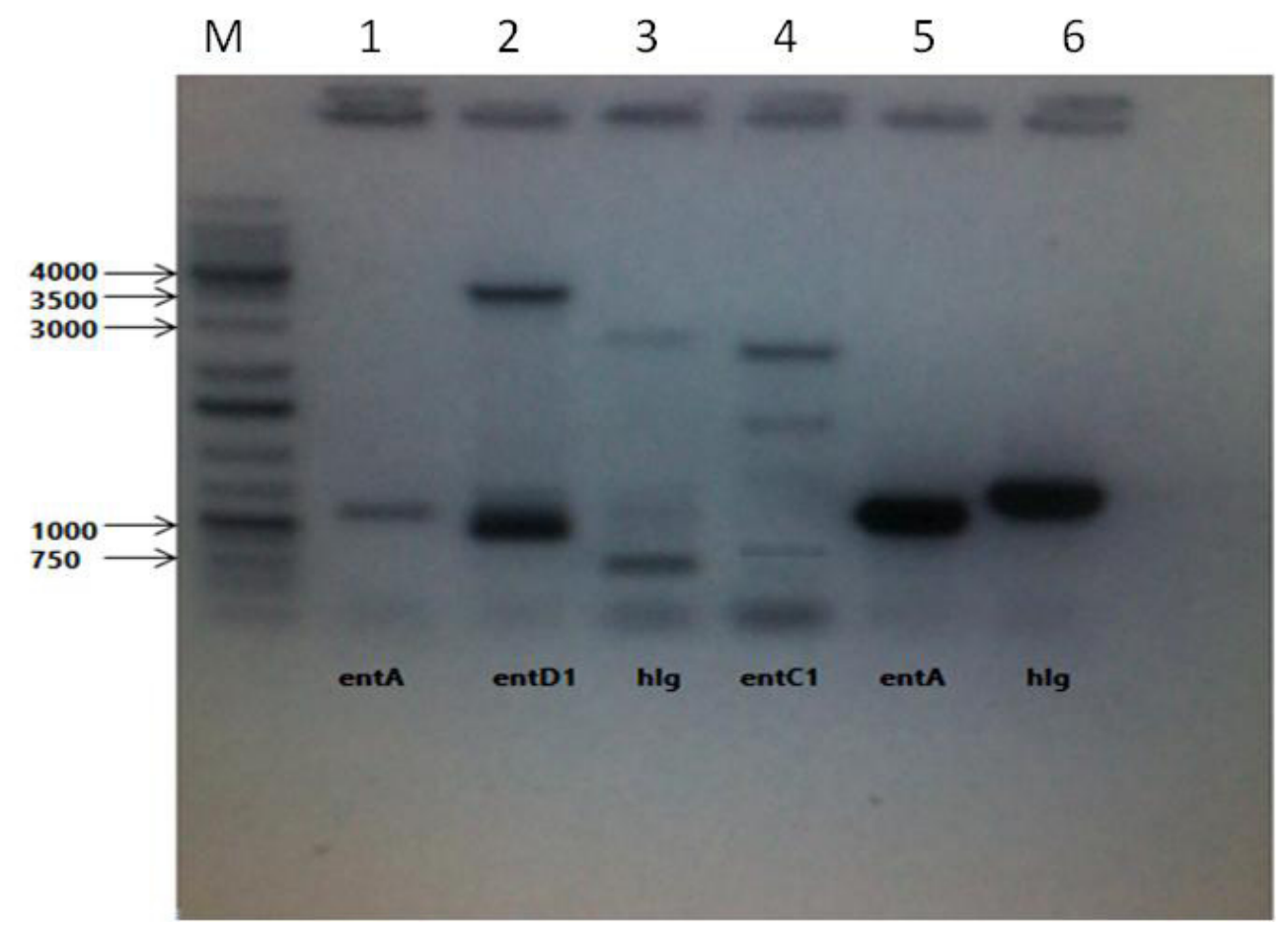

Fig. 3. Photo of agarose gel showing amplicons of PCR product resulting from 35 PCR cycles, using four mixtures for $S$. xylosus 11 strain (isolated from beef).

Lane1 (entA), lane2 (entD1), lane3 (hlg), and lane4 (entC1), and using two mixtures for S. aureus 41 (isolated from pus); lane5 (entA), and lane 6 ( $h l g)$. Lane M: $1 \mathrm{k}$ bp plus DNA ladder marker.

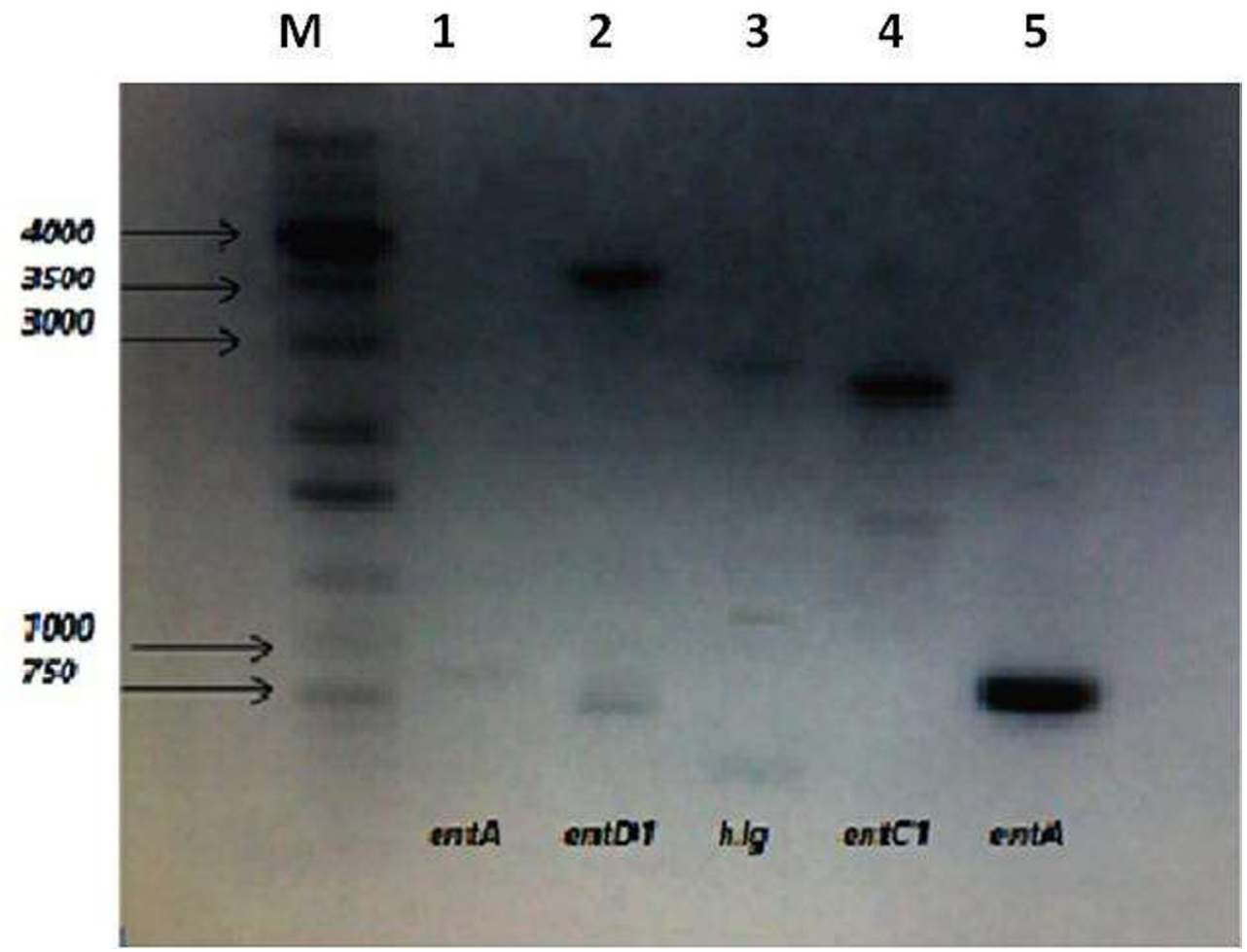

Fig. 4. Photo of agarose gel showing products of PCR after purification obtained amplicons. Four mixtures of the specific primers were used for $S$. xylosus 11 strain.

Lane1 (entA), lane2 (entD1), lane3 (hlg), and lane4 (entC1) and using one mixture for S. aureus 41; lane 5 (entA). Lane M: 1k bp DNA ladder marker. 
TABLE 4. Similarities between the obtained sequences from $S$. xylosus 11 and $S$. aureus 41 and gene sequences in the database

\begin{tabular}{|c|c|c|c|c|}
\hline Isolate & $\begin{array}{l}\text { Target } \\
\text { gene }\end{array}$ & Similar to & $\begin{array}{l}\text { Similarity } \\
\text { percentage }\end{array}$ & $\begin{array}{l}\text { Accession } \\
\text { number }\end{array}$ \\
\hline \multirow{4}{*}{ S. xylosus 11} & Ent $A$ & $\begin{array}{l}\text { Staphylococcus aureus strain } \text { ROF2 } \\
\text { enterotoxin A gene, partial cds }\end{array}$ & $79 \%$ & JN687471.1 \\
\hline & Ent $D_{1}$ & $\begin{array}{l}\text { Staphylococcus xylosus strain S170, complete } \\
\text { genome }\end{array}$ & $99 \%$ & CP013922.1 \\
\hline & $H l g$ & $\begin{array}{l}\text { Staphylococcus xylosus strain S170, complete } \\
\text { genome }\end{array}$ & $99 \%$ & CP013922.1 \\
\hline & Ent $C_{1}$ & $\begin{array}{l}\text { Staphylococcus aureus strain HUV05 plasmid } \\
\text { pHUV05-03, complete sequence }\end{array}$ & $81 \%$ & CP007679.1 \\
\hline S. aureus 41 & Ent $A$ & $\begin{array}{l}\text { S.aureus enterotoxin A (entA) gene, complete } \\
\text { cds }\end{array}$ & $99 \%$ & AY827552.1 \\
\hline
\end{tabular}

Alignment and similarity percentages were obtained by blast program (https://blast.ncbi.nlm.nih.gov/Blast).

Many of the genes responsible for virulence factors are located in strain-specific genetic elements such as plasmids, transposons, bacteriophages (Baba et al., 2002). The association of enterotoxin genes with movable genetic elements results in the horizontal transfer of superantigen genes between staphylococcal lineages, and they constitute an important role in the evolution of $S$. aureus and of CNS as pathogens (Vasconcelos \& da Cunha 2010).

Several authors have suggested the presence of enterotoxin and enterotoxin-like genes in genomes of $S$. xylosus, $S$. chromogenes, $S$. saprophyticus, S. lentus, S. warneri, S. sciuri and $S$. haemolyticus, S. hyicus, S. simulans, $S$. epidermidis, S. succinus, S. capitis, whereas the tst-1 gene was detected in $S$. xylosus, $S$. saprophyticus, S. warneri, S. hominis, and $S$. haemolyticus (Park et al., 2011). Fijałkowski et al. (2014) reported that among 30 isolates of $S$. xylosus isolated from milk, $16(53.3 \%)$ harbored from 1 to $10 \mathrm{SAg}$ genes. In total, in $16 \mathrm{SAg}$ positive $S$. xylosus, 11 different enterotoxin genes were detected: sec, sed, seg, seh, sei, selm, seln, selo, selp, ser, selu and one etd gene encoding exfoliative toxin D. The most prevalent genes were ser, selu and selo. Among all the positive isolates of $S$. xylosus, a total of 14 different SAg gene combinations were detected. One combination was repeated in 3 isolates, whereas the rest were detected only once. Piechota et al. (2014) detected staphylococci enterotoxin genes in Staphylococcus species isolated from milk samples from which $22(13.7 \%)$ were coagulase- negative staphylococci (CNS), among them in $9(11.4 \%)$ isolates of $S$. xylosus, $5(16.7 \%) S$. sciuri, 3 (10.3\%) S. epidermidis and in $5(22.7 \%)$ Staphylococcus spp. In some CNS 2 or 3 genes were detected simultaneously. Among the investigated enterotoxin genes, $\mathrm{sec}$ was the most prevalent (70\%). The genes encoding enterotoxin $\mathrm{B}$ and D were detected in $5(16.7 \%)$ and $6(20 \%)$ isolates, respectively. The lowest number of isolates had sea and see genes. Nunes et al. (2015) reported the presence of $S$. saprophyticus, S. sciuri, S. xylosus, S. carnosus, S. succinus, $S$. epidermidis, and $S$. hominis in commercial and artisanal salami collected in the municipality of Rio de Janeiro, Brazil. Fifteen strains harbored multiple enterotoxin genes, with high incidence of $\mathrm{seb} / \mathrm{sec}$ and sea $(57 \%$ and $50 \%)$, respectively; intermediate incidence of $\mathrm{sed} / \mathrm{seh} / \mathrm{selm}$ and sei/ seln/tst-H (33\% and 27\%), respectively and low incidence of see/selj/selo and seg, (13\% and $1 \%$ ). Fowoyo \& Ogunbanwo (2016) isolated 255 CNS isolates from 6 traditional fermented food from North Central Nigeria. These isolates were identified as $S$. epidermidis, $S$. simulans, $S$. xylosus, S. kloosii, and $S$. caprae, CNS isolates producing enterotoxins SEA, SEB, SEC, and SED were detected in $61(23.9 \%), 19(7.5 \%), 9$ $(3.5 \%)$, and $8(3.1 \%)$ of examined food samples, respectively.

Identity of the selected strain S. xylosus 11 was confirmed by amplification and alignment of $16 \mathrm{~S}$ rRNA gene which showed $99 \%$ similarity with S. xylosus strain and submitted in Genbank under accession number MH118574 (Fig. 5). 


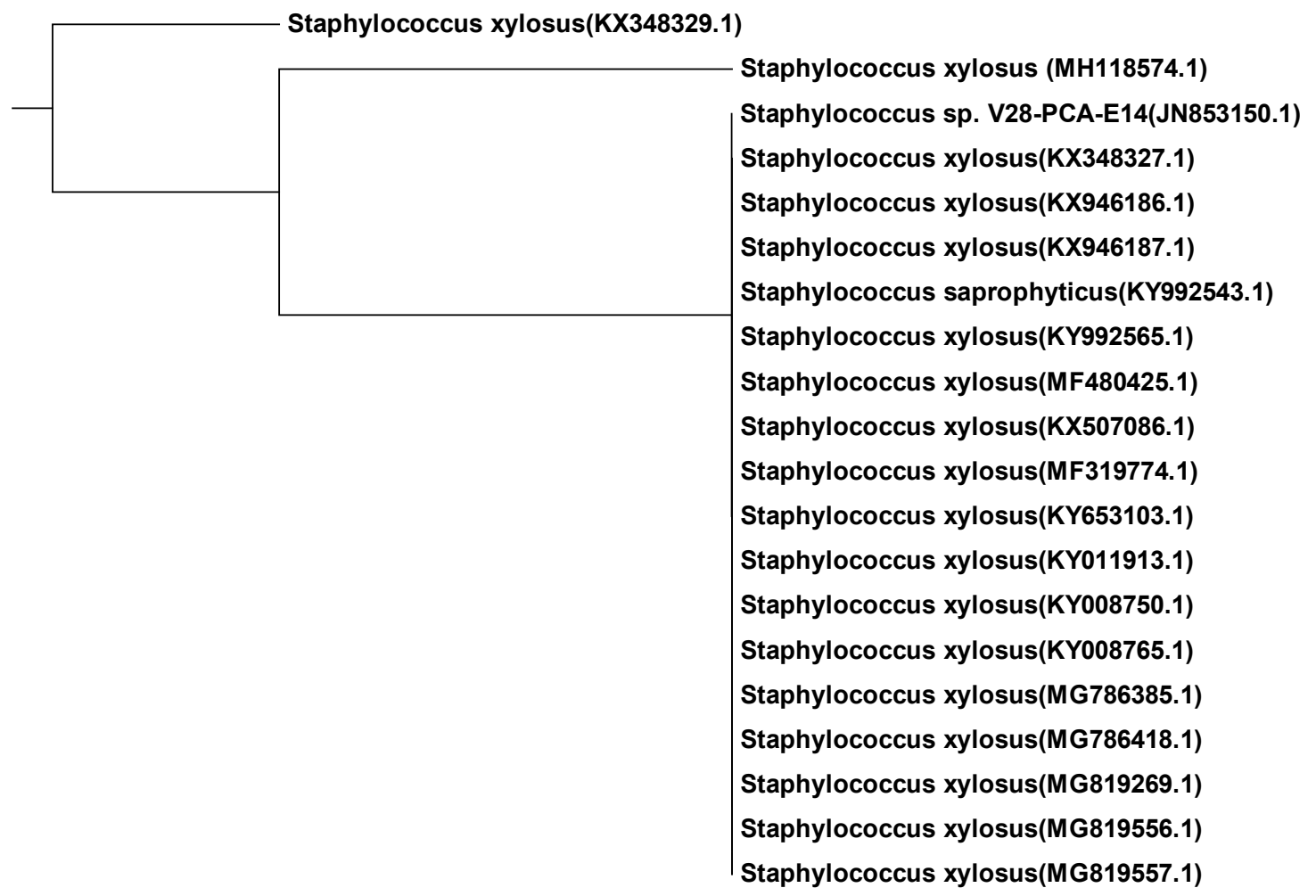

0.000100

Fig. 5. Phylogenetic tree of Staphylococcus xylosus 11.

Staphylococcus xylosus is a commensal of the skin of humans and animals persists in soils and on surfaces (Shale et al., 2005) and can be found in various niches (Nimrat et al., 2006). It is a ubiquitous bacterium naturally present in food and is one of the major starter cultures used for meat fermentation. Meanwhile, few strains could potentially be hazardous and are related to animal opportunistic infections (Dordet-Frisoni et al., 2007). S. xylosus in addition to its ability to form biofilms (Planchon et al., 2006), the ubiquity of $S$. xylosus might be explained by its ability to adapt to different environments. Also, S. xylosus had been previously reported as one of the most prevalent CNS species involved in bovine intramammary infections contaminating produced milk (Feßler et al., 2010) and one with the highest percentage of genes encoding enterotoxins (Piechota et al., 2014 and Nunes et al. 2015). However, distinguishing clinically significant pathogenic strains from those that are only sample contaminants is one of the greatest problems faced by clinical laboratories (Cunha et al., 2006).

\section{Conclusion}

Various studies featured Staphylococci as important pathogens and pointed out their toxigenic potential confirming that greater attention had to be given to such microorganisms, which are still often considered by other researchers to be simply contaminants.

Further investigation on environmental factors and elucidation of the regulation mechanisms interfering with virulent genes expression in CNS must be evaluated as well. The ability of Staphylococci food model strains to produce enterotoxins and their drug multi-resistance character must be examined when evaluating the safety hazards of food poisoning. Safety measures should be taken to reduce or totally remove the occurrence of Staphylococci in foods.

\section{References}

Azih, A. and Enabulele, I. (2013) Species distribution and virulence factors of coagulase-negative 
staphylococci isolated from clinical samples from the University of Benin teaching hospital, Edo State, Nigeria. J. Nat. Sci. Res. 3(9), 38-44.

Baba, T., Takeuchi, F. and Kuroda, M. (2002) Genome and virulence determinants of high virulence community-acquired MRSA. The Lancet. 359,1819-1827.

Babic, I., Markov, K. and Kovacevi, D. (2011) Identification and characterization of potential autochthonous starter cultures from a Croatian 'brand' product 'slavonski kulen'. J. Meat. Sci. 88 (3), 517-524.

Baird-Parker, A.C., Holbrook, R. and Anderson, J.M. (1969) The performance of a stable version of Baird-Parker's medium for isolating Staphylococcus aureus. J. App. Bact. 32(2), 187.

Becker, K., Heilmann, C. and Peters, G. (2014) Coagulase-negative staphylococci. Clin. Microbiol. Rev. 27(4), 870-926. doi: 10.1128/CMR.00109-13.

Bergdoll, M.S. (1995) Importance of staphylococci that produce nanogram quantities of enterotoxin. $J . \mathrm{Zbl}$. Bakt. 282, 1-6.

Campoccia, D., Montanaro, L. and Arciola, C.R. (2006) The significance of infection, related to orthopedic devices and issues of antibiotic resistance. Biomaterials, 27, 2331-2339.

Casadevall, A. and Pirofski, L.A. (2003) The damageresponse framework of microbial pathogenesis. Nat. Rev. Microbiol. 1, 17-24.

Chessbrough, M. (2000) Biochemical tests to identify bacteria. In: "Laboratory Practice in Tropical Countries", Cheesbrough, M. (Ed.), Vol. 2, pp. 6370, Cambridge University Press, UK.

Chiang, Y.C., Liao, W.W., Fan, C.M., Pai, W.Y., Chiou, C.S. and Tsen, H.Y. (2008) PCR detection of staphylococcal enterotoxins (SEs) N, O, P, Q, R, U, and survey of SE types in Staphylococcus aureus isolates from food-poisoning cases in Taiwan. Int. J. Food Microbiol. 121, 66-73.

Christie, R. and Wilson, H. (1941) Plate coagulase and fibrinolysin tests for staphylococci. Aust. J. Exp. Biol. Med. Sci. 10, 208.

Chu, V.H., Woods, C.W., Miro, J.M., Hoen, B., Cabell,
C.H., Pappas, P.A., Federspiel, J., Athan, E., Stryjewski, M.E., Nacinovich, F., Marco, F., Levine, D.P., Elliott, T.S., Fortes, C.Q., Tornos, P., Gordon, D.L., Utili, R., Delahaye, F. and Corey, G.R. (2008) Emergence of coagulase-negative staphylococci as a cause of native valve endocarditis. J. Clin. Infect. Dis. 46(2),232-342.

Collee, J.G. and Marr, W. (1996) Specimen collection, culture containers and media. In: " Practical Medical Microbiology", Collee, J.G. Fraser, A.G., Marmion, B.P. and Simmons, A. (Ed.), pp. 95-111. Mackie and MacCarthey. Churchill Livingstone, New York, London, Tokyo.

Cunha, M.L.R.S., Peresi, E., Calsolari, R.A.O. and Araújo, J.P. (2006) Detection of enterotoxins genes in coagulase-negative Staphylococci isolated from foods. Braz. J. Microbiol. 37, 70-74.

da Cunha, A.L., Zhou, J. and Do, M.N. (2006) The nonsubsampled contourlet transform: Theory, design, and applications. IEEE Trans. Image Precess, 15, 3089-3101.

Dordet-Frisoni, E., Dorchies, G., Araujo, C.D., Talon, R. and Leroy, S. (2007) Genomic diversity in Staphylococcus xylosus. J. App. Environ. Microbiol. 73(22), 7199-7209.

El-Jakee, J.K., Aref, N.E., Gomaa, A., El-Hariri, M.D., Galal, H.M., Omar, S.A. and Samir, A. (2013) Emerging of coagulase-negative staphylococci as a cause of mastitis in dairy animals: An environmental hazard. International Journal of Veterinary Science and Medicine, 1(2), 74-78.

El-Zawahry, Y.A., Reda, F.M. and Azazy, W.M. (2013) Synergistic effects of combination treatment between certain plant extracts and some antibiotics on the resistance of pathogenic bacteria against some common antibiotics. Life Sci. J. 10(4), 3477-3489. (ISSN:1097-8135). http://www.lifesciencesite.com.

Feßler, A.T., Billerbeck, C., Kadlec, K. and Schwarz, S. (2010) Identification and characterization of methicillin-resistant coagulase-negative staphylococci from bovine mastitis. J. Antimicrob. Chemother. 65, 1576-1582.

Fijałkowski, K., Struk, M., Karakulska, J., Paszkowska, A., Giedrys-Kalemba, S., Masiuk, H., CzernomysyFurowicz, D. and Nawrotek, P. (2014) Comparative analysis of superantigen genes in Staphylococcus 
xylosus and Staphylococcus aureus isolates collected from a single mammary quarter of cows with mastitis. J. Microbiol. 52(5), 366-372.

Foster, T.J. (2004) The Staphylococcus aureus “superbug”. J. Clin. Invest. 114, 1693-1696.

Foster, T.J. (2005) Immune evasion by staphylococci. $J$. Nat. Rev. Microbiol. 3, 948-958.

Fowoyo, P.T. and Ogunbanwo, S.T. (2016) Virulence and toxigenicity of coagulase-negative staphylococci in Nigerian traditional fermented foods. Can. J. Microbiol. e- First Article: pp.1-7.

Freer, J.H. and Arbuthnott, J.P. (1982) Toxins of Staphylococcus aureus. Pharmacol. Ther. 19, 55106.

Gillespie, B.E., Headrick, S.I., Boonyayatra, S. and Oliver, S.P. (2009) Prevalence and persistence of coagulase-negative Staphylococcus species in three dairy research herds. Vet. Microbiol. 134, 65-72.

Gray, G.S. and Kehoe, M. (1984). Primary sequence of the $\alpha$-toxin gene from Staphylococcus aureus. Wood 46. Infect. Immun. 46, 615-618.

Guimaråes, F.d.F., Nøbrega, D.B., Richini-Pereira, V.B., Marson, P.M., Pantoja, J.C.d.F. and Langoni, H. (2013) Enterotoxin genes in coagulase-negative and coagulase-positive staphylococci isolated from bovine milk. J. Dairy Sci. 96, 2866-2872.

Gundogan, N. and Ataol, O. (2013) Biofilm, protease and lipase properties and antibiotic resistance profiles of staphylococci isolated from various foods. Afr. J. Microbiol. Res. 7(28), 3582-3588.

Herman, A. (1991) Superantigens, Mechanism of T-cell stimulation and role in immune responses. Annu. Rev. Immunol. 9, 745-772.

Holt, J.G., Krieg, N.R., Sneath, P.H.A., Staley, J.T., and Williams, S.T. (1994) "Bergey's Manual of Determinative Bacteriology". $9^{\text {th }}$ ed. Baltimore: The Williams \& Wilkins Co, USA.

Huy, Y.H. (1994) "Foodborne Disease Handbookdiseases Caused by Bacteria". New York: Marcel Dekker.

Jarraud, S. (1999) Involvement of enterotoxins G and I in staphylococcal toxic shock síndrome and staphylococal scarlet fever. J. Clin. Microbiol. 37, 2446-2449.

Kadariya, J., Smith, T.C., and Thapaliya, D. (2014) Staphylococcus aureus and Staphylococcal foodborne disease: An ongoing challenge in public health. J. Biomed. Res. Int. 8,1-9.

Klaenhammer, I.R. (1988) Partial characterization of bacteriocins produced by Staphylococcus aureus isolates from milk and milk products. Bioehcmic. 70, 337-349.

Kloos, W.E. and Bannerman, T.L. (1995) Staphylococcus and Micrococcus. In: "Manual of Clinical Microbiology", Murray, P.R. Baron, E.J., Pfaller, M.A., Tenover, F.C., Yolken, R.H. (Ed.), pp. 282-298. American Society Microbiology, Washington.

Klotz, M. S., Opper, K. Heeg and Zimmermann, S. (2003) Detection of Staphylococcus aureus enterotoxins A to D by real-time fluorescence PCR assay. J. Clin. Microbiol. 41(10), 4683-4687.

Koneman, E.W., Allen, S.D., Janda, W.M., Schreckenberger, P.C. and Winn, Jr.W.C. (1997) "Color Atlas and Textbook of Diagnostic Microbiology", J.B. Lippincott (Ed.), Philadelphia, pp. 1395.

Le Loir, Y., Baron, F. and Gautier, M. (2003) Staphylococcus aureus and food poisoning. J. Genet. Mol. Res. 2, 63-76.

Lennette, E.H., Spaulding, B.H. and Truant, J.B. (1979) "Manual of Clinical Microbiology", 2n (ed). AMS Press, Washington D.C.

Lisa, R.W. (2004) Staphylococcus aureus exfoliative toxins: How they cause disease. J. Derm. Foundat. 122, 1070-1077.

Longauerova, A. (2006) Coagulase negative staphylococci and their participation in pathogenesis of human infections. Bratisl. Lek. Listy. 107(11-12), $448-452$

Lowy, FD. (1998) Medical progress: Staphylococcus aureus infections. The New England Journal of Medicine, 339(8), 520-532.

Mathur, T., Singhal, S., Khan, S., Upadhyay, D.J., Fatma, T. and Rattan, A. (2006) Detection of 
biofilm formation among the clinical isolates of Staphylococci. Indian. J. Med. Microbiol. 24(1), 25-29.

Merlino, J., Goll, R. and Robertson, G.J. (1996) Application of Lipovitellin salt Mannitol agar for screening, isolation and presumptive identification of $S$. aureus in teaching hospital. J. Clin. Microbiol. 34, 3012-3015.

Murray, P.R., Baron, E.J., Jorgensen, J.H., Landry, M.L. and Pfaller, M.A. (2007) "Manual of Clinical Microbiology", $9^{\text {th }}$ ed., ASM Press, Washington, D.C.

NCCLS (National Committee for Clinical Laboratory Standards) (1999) "Methods for Dilution Antimicrobial Susceptibility Tests for Bacteria that Grow Aerobically", $4^{\text {th }}$ ed. Approved standard M7A4: Wayne, Pa.

Nimrat, S., Siriboonlamom, S., Zhang, S., Xu, Y. and Vuthiphandchai, V. (2006) Chilled storage of white shrimp (Litopenaeus vannamei) spermatophores. Aquaculture, 261, 944-951.

Novick, R.P., Schlievert, P. and Ruzin, A. (2001) Pathogenicity and resistance islands of staphylococci. Microbes Infect. 3, 585-594.

Nunes, R.S.C., Aguila, E.M.D. and Paschoalin, V.M.F. (2015) Safety evaluation of the coagulase-negative Staphylococci microbiota of Salami: Superantigenic toxin production and antimicrobial resistance. BioMed Research International, Volume 2015, Article ID 483548, 17 pages

Osek, J. (2000) Virulence factors and genetic relatedness of Escherichia coli strains isolated from pigs with post-weaning diar-rhoea. Vet. Microbiol. 71, 211222.

Park, J.Y., Fox, L.K., Seo, K.S., McGuire, M.A., Park, Y.H., Rurangirwa, F.R., Sischo, W.M. and Bohach, G.A. (2011) Detection of classical and newly described staphylococcal super antigen genes in coagulase-negative staphylococci isolated from bovine intramammary infections. J. Vet. Microbiol. 147,149-154.

Piechota, M., Kot, B., Zdunek, E., Mitrus, J., Wicha, J., Wolska, M.K. and Sachanowicz, K. (2014) Distribution of classical enterotoxin genes in staphylococci from milk of cows with and without mastitis and the cowshed environment. J. Vet. Sci. 3 (17), 407-411.

Planchon, S., Gaillard-Martinie, B., Dordet-Frisoni, E., Bellon-Fontaine, M.N., Leroy, S., Labadie, J., Hebraud, M. and Talon, R. (2006) Formation of biofilm by Staphylococcus xylosus. Int. J. Food Microbiol. 109, 88-96.

Reda, F.M., El-Zawahry, Y.A. and Omar, A.R. (2017) Synergistic effect of combined antibiotic and methanol extract of Eucalyptus camaldulensis leaf against Staphylococcus aureus and Pseudomonas aeruginosa. Int. J. Appl. Sci. Biotechnol. 5(4), 486497.

Rosec, J.P. and Gigaud, O. (2002) Staphylococcal enterotoxin genes of classical and new types detected by PCR. in France. J. Food Microbiol. 77, 61-70.

Sambrook, J. and Russell, D. (2001) "Molecular cloning: A Laboratory Manual", $3^{\text {rd }}$ d. Cold Springs Harbour Press.

Sambrook, J. Fritsch, E.F. and Maniatis, T. (1989) "Molecular Cloning: A Laboratory Manual". Cold Spring Harbor Laboratory, New York.

Shale, K., Lues, J.F.R., Venter, P. and Buys, E.M. (2005) The distribution of Staphylococcus sp. on bovine meat from abattoir deboning rooms. J. Food Microbiol. 22, 433-438.

Supersac, G., Piémont, Y., Kubina, M., Prévost, G. and Foster, T.J. (1998) Assessment of the role of gamma-toxin in experimental endophthalmitis using a hlg-deficient mutant of Staphylococcus aureus. J. Microb. Pathog. 24, 241-51.

Tarekgne, E., Skeie, S., Rudi, K., Skjerdal, T. and Narvhus, J.N. (2015) Staphylococcus aureus and other Staphylococcus species in milk and milk products from Tigray region, Northern Ethiopia. Afr. J. Food Sci. 9(12), 567-576.

Vaidieki, K., Jyakumer, S. and Thilagavathi, G. (2007) Investigation on the antimicrobial activity of RF air plasma and Azadirachtin treated cotton fabric. $J$. Instrum Soc India, 37(4), 258-266.

Vasconcelos, N.G. and da Cunha, M.L.R.S. (2010) Staphylococcal enterotoxins: Molecular aspects and detection methods. J. Pub. Health Epidemiol. 2, 29-42. 
Vianello, M.A. (2006) Genotypic characterization of virulence factors and your regulator agr in strains of Staphylococcus aureus sensitive to oxacillin. PhD Thesis, Faculty of Pharmaceutical Sciences- USP, São Paulo.

Vogel, L., Jacobus, H.S., Spaargaren, J., Suiker, I., and Dijkshoorn, L. (2000) Biofilm production by Staphylococcus epidermidis isolates associated with catheter related bacteremia. J. Diagn. Microbiol. Infect. Dis. 30, 138-141.
Ye, J., Coulouris, G., Zaretskaya, I., Rozen, I. and Madden, L. (2012) Primer-BLAST: A tool to design target-specific primers for polymerase chain reaction. J. BMC. Bioinformatics, 13(134), 1-11.

(Received 1/11/2017) accepted 6/ 6/2018)

\section{انتشار عوامل الضراوة في المكورات العنقودية المعزولة من العينات السريرية والأطعمة في مصر \\ فيفي محمد رضا، رشاد محمد كبيش، عزة عبد العزيز أبو زيل و مروة نصر الشعراوى

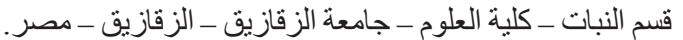

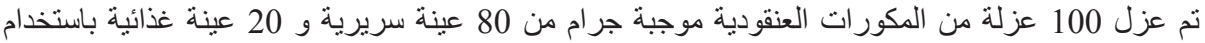

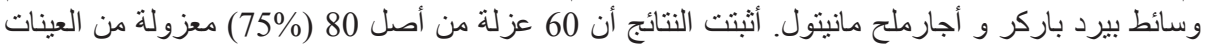

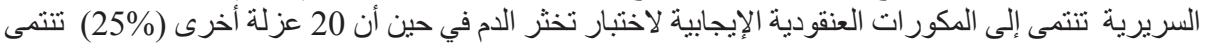

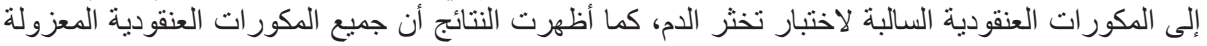

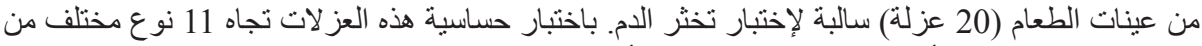

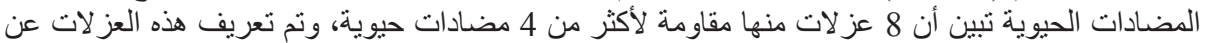

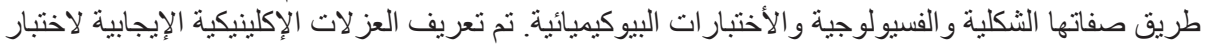

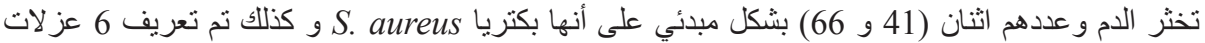

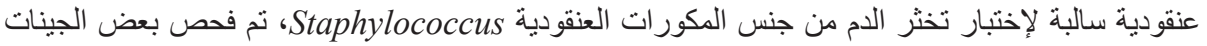

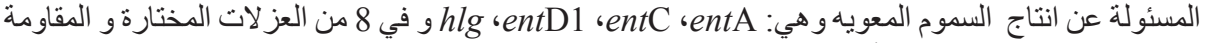

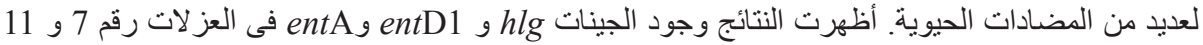

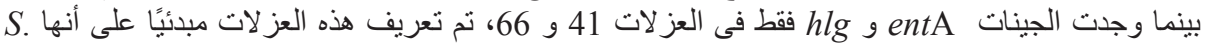

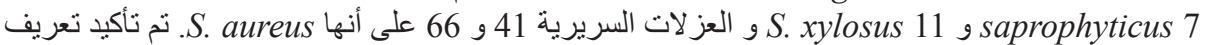
16S rRNA التي أظهرت تشابه S. Sylosus 11

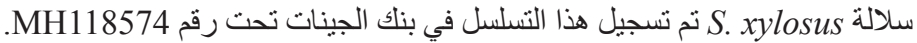

